\title{
Iodine status in European women in New Zealand with moderate selenium deficiency
}

\author{
Ljiljana Jowitt $^{* *}$ and Mark Duxbury ${ }^{2}$ \\ ${ }^{1}$ Faculty of Health and Environmental Sciences, School of Interprofessional Health Studies, 90 Akoranga Drive, North Shore Campus, PO Box 92006, 1020, \\ Auckland, New Zealand \\ ${ }^{2}$ Faculty of Health and Environmental Sciences, School of Applied Sciences, 55 Wellesley Street East, City Campus, PO Box 92006, 1142, Auckland Central, New
} Zealand

\begin{abstract}
For the optimal function of thyroid gland, adequate intakes of iodine and selenium are required. Since iodine is essential component of the thyroid hormones, its insufficiency leads to inadequate hormone production and further to inadequate tissue response (hypothyroidism), goitre, stillbirth and miscarriages, and growth retardation. According to the World Health Organisation the recommended median urinary iodine concentrations (UIC) are the best indicators of iodine nutrition. The WHO defines iodine sufficiency in an adult population as a median UIC of $>100 \mu \mathrm{g} / \mathrm{L}$ in spot urine samples. Iodine deficiency was and still is a problem in New Zealand. In September 2009 the mandatory fortification of all bread with iodized salt was introduced. Therefore, the primary aim of the study was to determine the levels of iodine in both groups, and the secondary aim of the study was to determine whether there is a relationship between selenium and iodine, and iodine and thyroid hormones in two groups of European women. Urinary iodine concentration was determined in spot samples by the new method called "Fast B", which is improved Sandell-Kolthoff reaction. The results of the study showed the mean urinary iodine level in the control group and the group of women with the Hashimoto's thyroiditis was $120.77 \pm 59.35$ (median UIC was $128.00 \mu \mathrm{g} / \mathrm{L}$ ), and $98.64 \pm 62.83$ (median UIC was $95.00 \mu \mathrm{g} / \mathrm{L}$ ), respectively. Estimated daily iodine intake of $150 \mu \mathrm{g} /$ day was achieved in five participants in the control group, and four participants in the group of women with Hashimoto's thyroiditis. Estimated median iodine intake in the control group and Hashimoto's group was 142.22 and 105.55, respectively, indicating mild iodine deficiency. There was no significant relationships found between iodine and selenium, and iodine and thyroid hormones in both groups. The results of the current study are in line with the results from larger studies carried out in New Zealand. Iodine intakes appear to have improved after the mandatory fortification of bread with iodised salt in 2009, although iodine deficiency is still a problem in New Zealand. Using an iodine fortified bread clearly made an impact on the overall iodine intake but not to the expected level. There was no association found between iodine and selenium, and iodine and thyroid hormones. Any possible interaction between selenium and iodine is still unclear.
\end{abstract}

\section{Introduction}

The synthesis of the major thyroid gland hormone thyroxine occurs along the hypothalamic-pituitary-thyroid axis (HPT axis). HPT axis represents a complex series of pathways and feedback mechanisms $[1,2]$. Adequate function of the HPT axis is critically dependent on the essential trace elements iodine, selenium and iron, although most closely associated are iodine and selenium [3]. The thyroid gland contains the highest iodine and selenium concentration among the human tissues and organs in the human body. For the optimal function of thyroid gland, adequate intakes of iodine and selenium are required [4]. Inadequate iodine intake can cause deficiency which might impair the synthesis of thyroid hormones, tetra iodothyronine (T4) and triiodothyronine (T3), whereas selenium is essential for the synthesis of selenoenzymes whose deficiency is implicated in disorders of thyroid hormone metabolism, and thyroid gland function.

The crucial step in thyroid hormone synthesis is the direct binding of TSH to the TSH receptors (TSH- $\mathrm{R}_{\mathrm{s}}$. [5]. Iodine is taken by thyrocytes from blood plasma through the actions of the integral plasma membrane glycoprotein sodium/iodide symporter (NIS), which mediates the active transport of iodine into the thyroid follicular cells [6]. The next step in thyroid hormone synthesis is the process of thyroglobulin ( $\mathrm{Tg}$ ) iodination, which occurs inside the lumen of thyroid follicles $[7,8]$. Thyroglobulin iodination requires iodide catalyzed by selenoenzyme thyroid peroxidase (TPO), and higher $\mathrm{H}_{2} \mathrm{O}_{2}$ concentrations generated in the apex of the thyrocytes, where selenium exerts one of its vital roles in peroxide degradation, cellular redox and transcription regulation, and thyroid hormone deiodination [3]. Overall, selenium plays a crucial role in the maintenance of metabolic, immune-endocrine, and cellular homeostasis, owing to its antioxidant and anti-inflammatory properties $[9,10]$. Selenium is an integral part of the iodothyronine deiodinases (selenoenzymes), that link selenium and iodide in a potentially important interrelationship in which one trace element might influence the metabolism of another [11]. Synthesized entirely by the thyroid gland, $\mathrm{T} 4$ acts as a prohormone to generate T3. The process of peripheral mono deiodination of T4 provides for the remaining $80 \%$ of $\mathrm{T} 3$ daily production in healthy people, whereas thyroid gland itself generates $20 \%$ of the T3 [12]. Biologically active $\mathrm{T} 3$ is essential for normal development, growth, neural differentiation, and cellular metabolism [13].

Iodine is an essential component of the thyroid hormones, T4 and T3, and makes $65 \%$ and $59 \%$ of their molecular weight respectively [14]. For adequate hormone supply, the thyroid gland has developed

Correspondence to: Ljiljana Jowitt, Faculty of Health and Environmental Sciences, School of Interprofessional Health Studies, 90 Akoranga Drive, North Shore Campus, PO Box 92006, 1020, Auckland, New Zealand, Tel: +649 9219999; E-mail: ljowitt@aut.ac.nz

Received: July 29, 2017; Accepted: August 24, 2017; Published: August 28, 2017 
an elaborate mechanism for concentrating iodine from the circulation and converting it to T4, which is then stored and released on demand. However, iodine insufficiency leads to inadequate hormone production and further to inadequate tissue response (hypothyroidism), goitre, stillbirth and miscarriages, growth retardation [15]. The most devastating toll is of the neurological and mental disorders resulting from the brain damage. In order to prevent iodine deficiency, the International Council for Control of Iodine Deficiency Disorders, the World Health Organisation, UNICEF, and the Food and Nutrition Board of the U.S. National Academy of Sciences, recommended dietary iodine intake (RDI) of about $150 \mu \mathrm{g} /$ day for adults being essential for the thyroid hormone synthesis [16].

Similarly, in Australia and New Zealand, the Estimated Average Requirement (EAR) and Recommended Dietary Intake (RDI) for adult women for iodine are 100 and $150 \mu \mathrm{g} /$ day. According to the World Health Organisation (WHO) and other international groups, the recommended median urinary iodine concentrations (UIC) are the best indicators of iodine nutrition [17]. The WHO defines iodine sufficiency (ID) in an adult population as a median UIC of $>100$ $\mu \mathrm{g} / \mathrm{L}$ in spot urine samples, providing no more than $20 \%$ of samples are $>50 \mu \mathrm{g} / \mathrm{L}$. The ranges where medians fall are far more important than the number. The ranges are arranged beginning with the severe iodine deficiency $(0-19 \mu \mathrm{g} / \mathrm{L})$, moderate deficiency $(20-49 \mu \mathrm{g} / \mathrm{L})$, mild deficiency $(50-99 \mu \mathrm{g} / \mathrm{L})$, optimal iodine nutrition $(100-199 \mu \mathrm{g} / \mathrm{L})$, and more than adequate iodine intake of (200-299 $\mu \mathrm{g} / \mathrm{L})$, and excessive iodine intake $(\geq 300 \mu \mathrm{g} / \mathrm{L})$ [18-20].

The signs and symptoms of ID in New Zealand were notified in the late 1800s and early 1900s and were characterized by endemic goiter and low UIC of less than $50 \mu \mathrm{g} / \mathrm{L}$. The major contributing factors for ID were low iodine concentrations of New Zealand soil and the reduction in the use of iodophors by the dairy industry [21]. In the early 1900s in order to decrease the incidence of endemic goiter in many parts of New Zealand, iodisation of table and cooking salt was introduced in 1924 at the level of $<40 \mathrm{mg} / \mathrm{kg}$, although it was increased in 1939 to $40-80$ $\mathrm{mg} / \mathrm{kg}$ [22]. Following this increase in iodisation of salt, the incidence of goiter has dropped from $61 \%$ to $1.1 \%$ in the 1950 s. For more than two decades iodine intake was adequate or more than adequate, owing to iodised table salt use and use of iodophors as equipment sanitizers in the dairy industry $[23,24]$. In the early 1990s, the use of iodophors decreased, and recommendations to reduce salt intake raised concerns that iodine intake might decrease. The study by Thomson et al. found that urine iodine concentrations were considerably lower than those previously reported [25]. However, iodine deficiency was and still is a problem in New Zealand and parts of Australia [26,27]. In September 2009 to prevent iodine deficiency, the mandatory fortification of all bread with iodized salt was introduced in both countries.

The primary aim of the study was to determine the levels of iodine in both groups and compare them with gold standards. The secondary aim of the study was to determine whether there is a relationship between selenium and iodine, and iodine and thyroid hormones in two groups of European women, control group and a group on medication with levothyroxine.

\section{Patients and method}

This study was conducted as a pilot, crossectional and observational. Volunteers in the study were 24 European women, who were self assigned into two groups, control group with healthy participants $(\mathrm{n}=13)$, and a group of women with Hashimoto's thyroiditis (HT) on medication with L-thyroxine $(n=11)$. Both groups presented with the moderate selenium deficiency. The plasma contents of selenium, TSH, T4, T3, creatinine, and e-GFR (Glomerular Filtration Rate) were determined. Any change in the participants' daily routine was not required. Plasma TSH, T3, and T4 were measured using competitive immunoassays technique by the LabTests Laboratories in Auckland. Serum selenium was measured using inductively coupled plasma dynamic reaction cell mass spectrometry by the Canterbury Health Laboratories in Christchurch, New Zealand. Urine samples were frozen and kept on $-20^{\circ} \mathrm{C}$ until analysis. Urinary iodine concentration (UIC) was determined in spot samples by the new method called "Fast B" at the AUT University Laboratory [28]. Fast B method is improved Sandell-Kolthoff reaction, which is simple, rapid, inexpensive, and reliable, and flexible [29] .

\section{Statistical analyses}

All statistical analyses were conducted using SPSS for windows (version 22.0, SPSS Inc., Chicago, Illinois, USA). Variables in the study were normally distributed, although TSH had skewed distribution and was $\log$ transformed before statistical analyses. Descriptive statistics (mean \pm S.D, and frequencies) were presented for baseline characteristics, while Pearson product-moment correlation coefficient investigated the relationships between iodine and selenium, and iodine and thyroid hormones in both groups of participants. From UICs, estimated daily intake of iodine was calculated. Values with a $\mathrm{p}<0.05$ were taken as significant.

\section{Results}

Women with Hashimoto's thyroiditis were older than women in the control group, $58.09 \pm 10.80$ and $52.69 \pm 7.40$ respectively. Both groups presented with the moderate selenium deficiency. The mean plasma selenium levels in the control group and the group of women with the Hashimoto's thyroiditis were $1.28 \pm 0.15$, and $1.32 \pm 0.17$ respectively. The mean urinary iodine level in the control group and the group of women with the Hashimoto's thyroiditis was $120.77 \pm$ 59.35 (median UIC was $128.00 \mu \mathrm{g} / \mathrm{L}$ ), and $98.64 \pm 62.83$ (median UIC was $95.00 \mu \mathrm{g} / \mathrm{L}$ ), respectively. Estimated daily iodine intake of $150 \mu \mathrm{g} /$ day was achieved in five participants in the control group, and four participants in the group of women with Hashimoto's thyroiditis. Estimated median iodine intake in the control group and Hashimoto's group was 142.22 and 105.55 , respectively. Pearson correlation analyses have shown no significant relationships between iodine and selenium, and iodine and thyroid hormones TSH, T4, and T3 in both groups. The mean plasma levels of creatinine and $e$ GFR were within optimal ranges in both groups.

\section{Discussion}

This study is based on self-reported presence or absence of thyroid disease. Participants in the study were European women $(n=24)$ who were self-assigned into the healthy control group $(n=13)$ and a group of women with Hashimoto's autoimmune thyroiditis on medication with Levothyroxine $(n=11)$. Both groups presented with the moderate selenium deficiency [30]. It has been suggested that maximal activity of selenoenzyme is reached at blood selenium levels above $1.27 \mu \mathrm{mol} / \mathrm{L}$, or according to the recent research by Rayman plasma selenium levels in the range of 1.6 to $1.9 \mu \mathrm{mol} / \mathrm{L}$ are considered optimal for thyroid and overall good health [31].Also the study by Karunasinghe et al. (2012) have suggested that the basic selenium requirement may vary with genotype for a number of variations in selenoprotein genes, suggesting that an effective dietary selenium intake for one person may be different from that for others. In the absence of this information, 
recommended plasma selenium levels should be in the range of 1.27 $1.90 \mu \mathrm{mol} / \mathrm{L}[32]$.

Plasma levels of TSH and T4 are higher in the group of women with Hashimoto's thyroiditis $(2.92 \pm 2.83 ; 14.27 \pm 2.45)$ than in the control group $(14.62 \pm 1.45)$ respectively. On the basis of these measurements, it is difficult to draw any conclusion about the iodine nutritional status of women in both groups, because TSH and T4 are not proper markers of urinary iodine concentrations (UIC) in this study sample [14]. However, currently, the most practical marker of community iodine nutrition is the median UIC in casual samples $(\mu \mathrm{g} / \mathrm{L})$, since about $90 \%$ of iodine is excreted in urine, which represents an indicator of the adequacy of the iodine intake of that population. According to the International Council for Control of Iodine Deficiency Disorders, the World Health Organisation, UNICEF, and the Food and Nutrition Board of the U.S. National Academy of Sciences, the minimal UIC for iodine sufficiency was set up at $100 \mu \mathrm{g} / \mathrm{L}$, which corresponds to a daily intake of $150 \mu \mathrm{g}$ of iodine [33]. Following these recommendations, after mandatory fortification of bread with iodised salt in 2009, women in the control group had a moderate sufficiency of iodine with the median UIC of $128.00 \mu \mathrm{g} / \mathrm{day}$, while women in the Hashimoto's group had mild iodine deficiency with the median UIC of $95.00 \mu \mathrm{g} /$ day. These figures suggest that the iodine status of New Zealand adults in this study sample is now likely to be adequate for the healthy population (Table 3 and 4 ). The UICs below $50^{\text {th }}$ percentile significantly differed between the two groups. Below the $20^{\text {th }}$ percentile, women in Hashimoto's group had severe iodine deficiency with UIC of $14 \mu \mathrm{g} / \mathrm{L}$, while women in the control group presented with the mild iodine deficiency of $63.80 \mu \mathrm{g} / \mathrm{L}$ (Table 2). Estimated median iodine intake in the control group and the group of women with Hashimoto's thyroiditis based on urine was $142.22 \mu \mathrm{g} /$ day and $105.55 \mu \mathrm{g} /$ day respectively, below RDI of $150 \mu \mathrm{g} /$ day in both groups; although, lower in the Hashimoto's group (Table 1). The presence of iodine and selenium deficiencies in this study is supported by the study of Brough, et al (2017) with mild ID and low selenium intake of postmenopausal women in New Zealand [34]. Median UIC was $57 \mu \mathrm{g} / \mathrm{L}$, while estimated median iodine intake based on urine was $138 \mu \mathrm{g} /$ day, below RDI (150 $\mu \mathrm{g} /$ day $)$. Another study by Edmonds et al. (2016) notified an improvement in iodine status from a median UIC of $53 \mu \mathrm{g} / \mathrm{L}$ reported in the 2008/2009 New Zealand Adult Nutrition Survey to $73 \mu \mathrm{g} / \mathrm{L}$ in the study, which was far below the recommended range by WHO/UNICEF/ICCIDD, although median urinary iodine excretion (UIE) of $127 \mu \mathrm{g} /$ day suggested that overall iodine status was likely to be adequate after mandatory fortification of bread in 2009[35].

Table 1. UIC and estimated dietary intake of iodine in both groups.

\begin{tabular}{|c|c|c|c|}
\hline \multicolumn{2}{|c|}{ Hashimoto's group n=11 } & \multicolumn{2}{c|}{ Control group n=13 } \\
\hline $\begin{array}{c}\text { UIC } \\
(\mu \mathrm{g} / \mathrm{L})\end{array}$ & $\begin{array}{c}\text { EDI of Iodine } \\
(\mu \mathrm{g} / \text { day })\end{array}$ & $\begin{array}{c}\text { UIC } \\
(\mu \mathrm{g} / \mathrm{L})\end{array}$ & $\begin{array}{c}\text { EDI of Iodine } \\
(\mu \mathrm{g} / \text { day })\end{array}$ \\
\hline 119 & 132.22 & 154 & 171.11 \\
\hline 11 & 12.22 & 128 & 142.22 \\
\hline 137 & 152.22 & 65 & 72.22 \\
\hline 180 & 200 & 128 & 142.22 \\
\hline 34 & 37.77 & 64 & 71.11 \\
\hline 68 & 75.55 & 161 & 178.88 \\
\hline 95 & 105.55 & 176 & 195.55 \\
\hline 14 & 15.55 & 111 & 123.33 \\
\hline 149 & 165.55 & 77 & 85.55 \\
\hline 190 & 211.11 & 141 & 156.67 \\
\hline 88 & 97.77 & 257 & 285.56 \\
\hline & & 63 & 70 \\
\hline & & 45 & 50 \\
\hline
\end{tabular}

Table 2. Means, SDs, and frequencies of estimated median iodine intake in both groups.

\begin{tabular}{|c|c|c|c|}
\hline \multicolumn{4}{|c|}{ Estimated median iodine intake } \\
\hline \multicolumn{3}{|c|}{ Hashimoto's group $n=11$} & Control group $n=13$ \\
\hline \multicolumn{2}{|c|}{ Mean } & 109.59 & 134.19 \\
\hline \multicolumn{2}{|c|}{ Median } & 105.55 & 142.22 \\
\hline \multicolumn{2}{|c|}{ Std. Deviation } & 69.81 & 65.94 \\
\hline \multirow{11}{*}{ Percentiles } & 10 & 12.89 & 58.00 \\
\hline & 20 & 24.44 & 70.89 \\
\hline & 25 & 37.77 & 71.67 \\
\hline & 30 & 60.44 & 74.89 \\
\hline & 40 & 93.33 & 108.22 \\
\hline & 50 & 105.55 & 142.22 \\
\hline & 60 & 136.22 & 148.00 \\
\hline & 70 & 157.55 & 168.22 \\
\hline & 75 & 165.55 & 175.00 \\
\hline & 80 & 186.22 & 182.21 \\
\hline & 90 & 208.89 & 249.56 \\
\hline
\end{tabular}

Continuous changes in the iodine supply to New Zealand population through the time, showed that iodine is already established factor in the onset of thyroid autoimmunity (TAI) [36]. In susceptible individuals, iodine overload causes a paradoxical block of the organification of iodide (the so-called Wolff-Chaikoff effect), and of the iodine intrathyrocyte transport by the sodium-iodide symporter (NIS). It was shown that iodide-induced hypothyroidism was precipitated by either prolonged excessive intracellular iodide concentration, or transition from iodine deficiency to iodine sufficiency or excess, that increased the incidence of autoimmune thyroiditis (AIT) and hypothyroidism, especially in young women [37]. Autoimmune disease affects thyroid gland more than any other organ in the body $[38,39]$. Hashimoto's thyroiditis (HT) is a primary and permanent hypothyroidism, and the most common autoimmune disease. Chronic inflammation of the thyroid endocrine tissue is the major characteristic of the autoimmune process.

In our study, women with Hashimoto's thyroiditis on medication with Levothyroxine, besides moderate selenium deficiency are now categorized as a group of women with ID which is less pronounced in the group of women without thyroid disorder. In our study, no association was found between selenium and iodine, and thyroid hormones (Table 5). However, several studies indicated that effects of selenium deficiency or excess on thyroid hormone biosynthesis in severe ID were more likely to be more pronounced than in mild ID [40-43]. Although, according to Rasmussen et al. (2011), optimal selenium status might help to prevent iodine deficiency disorders (IDD), particularly thyroid gland enlargement. The study by Shukri et al. (2014), suggested that severe selenium deficiency may exacerbate ID. However, the results from our study are in line with results from the larger study carried out in New Zealand [44]. The authors suggested that there was no association between plasma selenium and thyroid hormones, and selenium deficiency did not significantly affect study population with marginal iodine status. These findings might be applicable only to the healthy control group in the current study.

\section{Conclusions}

The results of the current study, with a relatively small sample size, are in line with the results from larger studies carried out in New Zealand. Iodine intakes appear to have improved after the mandatory fortification of bread with iodised salt in 2009, although ID is still a problem in New Zealand. Using an iodine fortified bread clearly made an impact on the overall iodine intake but not to the expected 
Table 3. Variables presented as means, SDs, median, and frequencies (Hashimoto's group).

\begin{tabular}{|c|c|c|c|c|c|c|c|c|}
\hline & & Age & TSH & T3 & T4 & T3/T4r & Selenium & Iodine \\
\hline \multicolumn{2}{|c|}{ Mean } & 58.09 & 2.92 & 4.42 & 14.27 & 0.32 & 1.32 & 98.64 \\
\hline \multicolumn{2}{|c|}{ Median } & 57.00 & 1.60 & 4.40 & 15.00 & 0.30 & 1.28 & 95.00 \\
\hline \multicolumn{2}{|c|}{ Std. Deviation } & 10.80 & 2.83 & 0.66 & 2.45 & 0.07 & 0.17 & 62.83 \\
\hline \multirow{11}{*}{ Percentiles } & 10 & 40.80 & 0.64 & 3.54 & 10.20 & 0.23 & 1.12 & 11.60 \\
\hline & 20 & 48.80 & 0.73 & 3.86 & 11.40 & 0.25 & 1.17 & 22.00 \\
\hline & 25 & 50.00 & 0.81 & 4.10 & 12.00 & 0.27 & 1.19 & 34.00 \\
\hline & 30 & 52.40 & 0.92 & 4.10 & 13.20 & 0.28 & 1.21 & 54.40 \\
\hline & 40 & 55.60 & 1.40 & 4.26 & 14.00 & 0.28 & 1.25 & 84.00 \\
\hline & 50 & 57.00 & 1.60 & 4.40 & 15.00 & 0.30 & 1.28 & 95.00 \\
\hline & 60 & 62.40 & 2.98 & 4.52 & 15.00 & 0.32 & 1.32 & 122.60 \\
\hline & 70 & 64.00 & 3.86 & 4.60 & 15.40 & 0.37 & 1.42 & 141.80 \\
\hline & 75 & 64.00 & 4.70 & 4.60 & 16.00 & 0.38 & 1.45 & 149.00 \\
\hline & 80 & 64.60 & 4.88 & 4.72 & 16.60 & 0.40 & 1.47 & 167.60 \\
\hline & 90 & 77.00 & 9.00 & 5.76 & 17.80 & 0.43 & 1.65 & 188.00 \\
\hline
\end{tabular}

Table 4. Variables presented as means, SDs, median, and frequencies (Control group).

\begin{tabular}{|c|c|c|c|c|c|c|c|c|}
\hline & & Age & TSH & $\mathrm{T} 3$ & $\mathrm{~T} 4$ & T3T4ratio & Selenium & Iodine \\
\hline \multicolumn{2}{|c|}{ Mean } & 52.69 & 2.07 & 4.76 & 14.62 & 0.33 & 1.28 & 120.77 \\
\hline \multicolumn{2}{|c|}{ Median } & 54.00 & 2.10 & 4.90 & 14.00 & 0.34 & 1.29 & 128.00 \\
\hline \multicolumn{2}{|c|}{ Std. Deviation } & 7.40 & 0.41 & 0.58 & 1.45 & 0.05 & 0.15 & 59.35 \\
\hline \multirow{11}{*}{ Percentiles } & 10 & 40.60 & 1.44 & 4.02 & 12.40 & 0.26 & 1.04 & 52.20 \\
\hline & 20 & 46.00 & 1.58 & 4.20 & 13.80 & 0.26 & 1.12 & 63.80 \\
\hline & 25 & 46.50 & 1.70 & 4.20 & 14.00 & 0.28 & 1.14 & 64.50 \\
\hline & 30 & 47.80 & 1.86 & 4.26 & 14.00 & 0.30 & 1.16 & 67.40 \\
\hline & 40 & 52.20 & 2.10 & 4.62 & 14.00 & 0.32 & 1.26 & 97.40 \\
\hline & 50 & 54.00 & 2.10 & 4.90 & 14.00 & 0.34 & 1.29 & 128.00 \\
\hline & 60 & 54.40 & 2.20 & 4.90 & 14.80 & 0.35 & 1.34 & 133.20 \\
\hline & 70 & 55.80 & 2.20 & 5.06 & 16.00 & 0.35 & 1.37 & 151.40 \\
\hline & 75 & 58.50 & 2.23 & 5.10 & 16.00 & 0.36 & 1.38 & 157.50 \\
\hline & 80 & 61.00 & 2.30 & 5.12 & 16.00 & 0.36 & 1.41 & 164.00 \\
\hline & 90 & 62.80 & 2.74 & 5.74 & 16.60 & 0.41 & 1.51 & 224.60 \\
\hline
\end{tabular}

Table 5. Relationships among variables iodine, selenium, and thyroid hormones.

\begin{tabular}{|c|c|c|c|c|c|}
\hline \multirow{2}{*}{\multicolumn{2}{|c|}{\begin{tabular}{|l|}
\multicolumn{2}{|c|}{ Pearson Correlation } \\
Coefficient
\end{tabular}}} & \multicolumn{2}{|c|}{ Control group $n=13$} & \multicolumn{2}{|c|}{ Hashimoto's group $n=11$} \\
\hline & & \multirow{2}{*}{$\begin{array}{c}\text { Selenium } \\
-.026\end{array}$} & \multirow{2}{*}{$\begin{array}{c}\text { Iodine } \\
.291\end{array}$} & \multirow{2}{*}{$\begin{array}{c}\text { Selenium } \\
-.013\end{array}$} & \multirow{2}{*}{$\begin{array}{l}\text { Iodine } \\
-.006\end{array}$} \\
\hline$\Delta$ & & & & & \\
\hline Age & Sig. & .934 & .335 & .969 & .985 \\
\hline \multirow{2}{*}{ TSH } & & -.095 & .275 & -.040 & .107 \\
\hline & Sig. & .757 & .363 & .908 & .754 \\
\hline \multirow{2}{*}{$\mathrm{T} 3$} & & .006 & -.169 & .475 & -.216 \\
\hline & Sig. & .986 & .580 & .140 & .523 \\
\hline \multirow{2}{*}{$\mathrm{T} 4$} & & -.022 & .206 & .275 & -.140 \\
\hline & Sig. & .942 & .500 & .413 & .681 \\
\hline \multirow{2}{*}{ Selenium } & & & -.173 & & -.252 \\
\hline & Sig. & & .571 & & .454 \\
\hline \multirow{2}{*}{ Iodine } & & -.173 & & -.252 & \\
\hline & Sig. & .571 & & .454 & \\
\hline \multirow{2}{*}{ T3/T4ratio } & & .021 & -.248 & .037 & .009 \\
\hline & Sig. & .945 & .414 & .914 & .980 \\
\hline
\end{tabular}

**. Correlation is significant at the 0.01 level (2tailed)

*. Correlation is significant at the 0.05 level (2tailed).

level. Besides moderate selenium deficiency, at least half of the study participants had severe or mild ID in both groups. Considering the age of our study participants, women with Hashimoto's autoimmune thyroiditis, we might assume that they experienced iodine sufficiency or excess, or iodine insufficiency which could trigger autoimmune thyroid disease. Iodine is already recognized as established factor in the onset of thyroid autoimmunity. Also, in the study there was no association found between iodine and selenium, and iodine and thyroid hormones.
Any possible interaction between selenium and iodine is still unclear. It is necessary to have adequate monitoring of urinary iodine levels on a population level in order to detect further trends. It is essential to ensure New Zealanders are achieving adequate iodine intake.

\section{Acknowledgments}

I would like to thank you Mark Duxbury who determined urinary iodine concentration (UIC) in spot urine samples by the new method called "Fast B" at the AUT University Laboratory. Also, I am very thankful for the financial support I received from the School of Interprofessional Health Studies, and help from my colleagues in the recruitment of participants. All participants in the study read the Participants Information Sheet and gave Written Consent. The Auckland University of Technology Ethics Committee (AUTEC) No. 13/17, according to the Declaration of Helsinki, approved the study protocol.

\section{References}

1. Senese R, Cioffi F, de Lange P, Goglia F, Lanni A (2014) Thyroid: biological actions of 'nonclassical' thyroid hormones. J Endocrinol 221: R1-12. [Crossref]

2. McAninch EA, Bianco AC (2014) Thyroid hormone signaling in energy homeostasis and energy metabolism. Ann N Y Acad Sci 1311: 77-87. [Crossref]

3. Köhrle J, Jakob F, Contempré B, Dumont JE (2005) Selenium, the thyroid, and the endocrine system. Endocr Rev 26: 944-984. [Crossref]

4. Schomburg L, Köhrle J (2008) On the importance of selenium and iodine metabolism for thyroid hormone biosynthesis and human health. Mol Nutr Food Res 52: 12351246. [Crossref] 
5. Chiamolera MI, Wondisford FE (2009) Thyrotropin-releasing hormone and the thyroid hormone feedback mechanism. Endocrinol 150: 1091-1096. [Crossref]

6. Dohán O, De la Vieja A, Paroder V, Riedel C, Artani M (2003) The sodium/iodide symporter (NIS): characterization, regulation, and medical significance. Endocrine reviews 24: 48-77. [Crossref]

7. Beckett GJ, Arthur JR (2005) Selenium and endocrine systems. J Endocrinol 184: 455465. [Crossref]

8. Duntas LH, Benvenga S (2015) Selenium: an element for life. Endocrine 48: 756-775. [Crossref]

9. Rayman MP (2009) Selenoproteins and human health: insights from epidemiological data. Biochim Biophys Acta 1790: 1533-1540. [Crossref]

10. Brown KM, Arthur JR (2001) Selenium, selenoproteins and human health: a review. Public Health Nutr 4: 593-599. [Crossref]

11. Arthur JR, Beckett GJ (1999) Thyroid function. Br Med Bull 55: 658-668. [Crossref]

12. Bianco AC, Kim BW (2006) Deiodinases: implications of the local control of thyroid hormone action. J Clin Invest 116: 2571-2579. [Crossref]

13. Tata JR (2013) The road to nuclear receptors of thyroid hormone. Biochim Biophys Acta 1830: 3860-3866. [Crossref]

14. Dunn JT (1998) What's happening to our iodine? J Clin Endocrinol Metab 83: 33983400. [Crossref]

15. Zimmermann MB (2009) Iodine deficiency. Endocr Rev 30: 376-408. [Crossref]

16. Dunn JT, Semigran MJ, Delange F (1998) The prevention and management of iodineinduced hyperthyroidism and its cardiac features. Thyroid 8: 101-106. [Crossref]

17. WHO, UNICEF (2007) Assessment of iodine deficiency disorders and monitoring their elimination: a guide for programme managers. WHO: Geneva

18. WHO, UNICEF, ICCIDD (2001) Assessment of iodine deficiency disorders and monitoring their elimination: a guide for programme managers. Assessment of iodine deficiency disorders and monitoring their elimination: a guide for programme managers. WHO:Geneva

19. Bourdoux P, Thilly CH, Delange F, Ermans AM, Dunn J, et al. (1986) A new look at old concepts in laboratory evaluation of endemic goiter. Towards the eradication of endemic goiter, cretinism, and iodine deficiency. 115-129.

20. Dunn JT, Crutchfield HE, Gutekunst R, Dunn AD, Bourdoux P, et al. (1993) Methods for measuring iodine in urine.

21. Purves HD (1974) The aetiology and prophylaxis of endemic goitre and cretinism. The New Zealnd experience. $N Z$ Med $J$ 80: 477-479. [Crossref]

22. Simpson FO, Thaler BI, Paulin JM, Phelan EL, Cooper GJ (1984) Iodide excretion in a salt-restriction trial. N Z Med J 97: 890-893. [Crossref]

23. Cooper GJ, Croxson MS, Ibbertson HK (1984) Iodine intake in an urban environment: a study of urine iodide excretion in Auckland. N Z Med J 97: 142-145. [Crossref]

24. Sutcliffe E (1990) Iodine in New Zealand milk. Food Tech NZ, 7, 32-38.

25. Thomson CD, Smith TE, Butler KA, Packer MA (1996) An evaluation of urinary measures of iodine and selenium status. J Trace Elem Med Biol 10: 214-222. [Crossref]

26. Thomson CD (2004) Selenium and iodine intakes and status in New Zealand and Australia. Br J Nutr 91: 661-672. [Crossref]
27. Australia NZ a (2009) Food Standards Australia New Zealand.

28. Gnat D, Dunn AD, Chaker S, Delange F, Vertongen F, et al. (2003) Fast colorimetric method for measuring urinary iodine. Clin Chem 49: 186-188. [Crossref]

29. Hussain H, Mohamud WNW (2006) A cost-effective modified micromethod for measuring urine iodine. Tropical biomedicine 23: 109-115.

30. Jowitt L (2017) Selenium and tyroid health in NZ European women. Integrat Mol Med 4: $1-5$.

31. Rayman MP (2012) Selenium and human health. Lancet 379: 1256-1268. [Crossref]

32. Karunasinghe N, Han DY, Zhu S, Yu J, Lange K, et al. (2012) Serum selenium and single-nucleotide polymorphisms in genes for selenoproteins: relationship to markers of oxidative stress in men from Auckland, New Zealand. Genes Nutr 7: 179-190. [Crossref]

33. WHO, UNICEF, ICCIDD (1994) Indicators for assessing iodine deficiency disorder and their control programs through salt iodization. WHO/NUT/94.6. WHO: Geneva.

34. Brough L, Gunn CA, Weber JL, Coad J, et al. (2017) Iodine and Selenium Intakes of Postmenopausal Women in New Zealand. Nutrients 9. [Crossref]

35. Edmonds JC, McLean RM, Williams SM, Skeaff SA (2016) Urinary iodine concentration of New Zealand adults improves with mandatory fortification of bread with iodised salt but not to predicted levels. Eur J Nutr 55: 1201-1212. [Crossref]

36. Bürgi H (2010) Iodine excess. Best Pract Res Clin Endocrinol Metab 24: 107-115. [Crossref]

37. Fountoulakis S, Philippou G, Tsatsoulis A (2007) The role of iodine in the evolution of thyroid disease in Greece: from endemic goiter to thyroid autoimmunity. Hormones (Athens) 6: 25-35. [Crossref]

38. McLeod DS, Cooper DS (2012) The incidence and prevalence of thyroid autoimmunity. Endocrine 42: 252-265. [Crossref]

39. Jacobson DL, Gange SJ, Rose NR, Graham NM (1997) Epidemiology and estimated population burden of selected autoimmune diseases in the United States. Clin Immunol Immunopathol 84, 223-243. [Crossref]

40. Zagrodzki P, Szmigiel H, Ratajczak R, Szybinski Z, Zachwieja Z (2000) The role of selenium in iodine metabolism in children with goiter. Environ Health Perspect 108: 67-71. [Crossref]

41. Rasmussen LB, Schomburg L, Köhrle J, Pedersen IB, Hollenbach B (2011) Selenium status, thyroid volume, and multiple nodule formation in an area with mild iodine deficiency. Eur J Endocrinol 164: 585-590. [Crossref]

42. Roti E, Minelli R, Gardini E, Bianconi L, Ronchi A, et al (1993) Selenium administration does not cause thyroid insufficiency in subjects with mild iodine deficiency and sufficient selenium intake. $J$ endocrinol invest 16: 481-484. [Crossref]

43. Shukri NH, Coad J, Weber J, Jin Y, Brough L (2014) Iodine and selenium intake in a sample of women of childbearing age in Palmerston North, New Zealand after mandatory fortification of bread with iodised salt. Food Nutri Sci 5: 382.

44. Thomson CD, McLachlan SK, Grant AM, Paterson E, Lillico AJ (2005) The effect of selenium on thyroid status in a population with marginal selenium and iodine status. $\mathrm{Br}$ J Nutr 94: 962-968. [Crossref]

Copyright: (C2017 Jowitt L. This is an open-access article distributed under the terms of the Creative Commons Attribution License, which permits unrestricted use, distribution, and reproduction in any medium, provided the original author and source are credited. 